\title{
A naturalists guide to mobile genetic elements
}

\author{
Tyler A. Elliott ${ }^{1}$ and J. Arvid Ågren ${ }^{2^{*}}$
}

\author{
Book details \\ Mobile DNA III, edited by Nancy L. Craig, Michael Chandler, Martin Gellert, Alan M. Lambowitz, Phoebe A. Rice, and \\ Suzanne B. Sandmeyer. Washington: American Society of Microbiology Press, 2015. Pp xxiv + 1305. H/b \$160.00
}

Keywords: Transposable elements, Genome evolution, Selfish DNA, Barbara McClintock, Mobile genetic elements

Transposable elements (TEs) make up a significant proportion of the DNA in the natural world. These self-replicating mobile genetic elements are almost three times as abundant as the second most common category, $\mathrm{ABC}$ transporters (Aziz et al. 2010). TEs are found in virtually all organisms and contribute more than half of the genetic material in a human cell.

Ever since the publication of the first edition in 1989, the Mobile DNA series has been a central reference point for researchers interested in the biology of TEs and it has been essential reading for students entering the field. 2015 marked the arrival of the third edition of this masterpiece (a second updated and expanded edition appeared in 2002). As usual, the editors have brought together a diverse set of authors. Across 55 chapters, spread across six sections (Introduction, Conservative Site-Specific Recombination, Programmed Rearrangements, DNA-only Transposons, LTR Retrotransposons, and Non-LTR Retrotransposons), they systematically cover several aspects of TE biology, with special attention paid to the molecular mechanisms of TEs (including chromosomal rearrangements, recombination, and the enzymes involved) to which it offers is an unrivalled introduction.

The whole book clocks in at a whopping 1305 pages. Commenting fairly on all aspects of the book is therefore next to impossible. Instead, we will focus on some

\footnotetext{
*Correspondence: arvid.agren@cornell.edu

2 Department of Molecular Biology and Genetics, Cornell University, Ithaca, NY 14853, USA

Full list of author information is available at the end of the article
}

emerging themes that stood out to us while reading the book. In particular, we will focus on how the details of molecular mechanisms of TEs reported in the book relate to current issues in the study of the TE evolution, and how these details can be harnessed to improve our understanding of the evolutionary causes and consequences of TEs.

In many ways, Mobile DNA III can be compared to early accounts of naturalists in new lands, or the detailed descriptions of species by taxonomists: it is rich in details on the structure of TEs and the molecular acrobatics they carry out to replicate and move themselves throughout genomes, but lighter on their evolutionary history. Without these details, however, those of us interested in the evolutionary biology of organisms or TEs would not have a place to start asking the relevant questions about diversity, abundance and history. Unfortunately, being able to compare TEs across taxa has often been hindered by several factors. Parsing out the repetitive content of genomes is difficult and a number of computational methods have been developed (Janicki et al. 2011). This wealth of options can be a curse though, as different methodologies across and between different genomes will often give different answers as to whether all TEs are detected or properly grouped together (Platt et al. 2016). TEs have a system of classification which mirrors the hierarchical taxonomic system employed by biologists for organisms, based upon the character of nucleic acid intermediates during replication (Finnegan 1989; Wicker et al. 2007). Partly as a consequence of this difficulty, genome papers vary widely in the detail to which the TE 
diversity is described, with some genome papers neglecting it completely (Elliott and Gregory 2015).

In light of the above issues, we can only echo recent calls to develop benchmark data sets against which to measure current and future means to annotate TEs, allowing TE annotations to be compared across different organisms (Hoen et al. 2015). Such community efforts of standardization should also take into account suggestions for a revised classification system, one which better incorporates the diversity of archaeal, bacterial and eukaryotic forms of mobile genetic elements, and based more upon the divergent phylogenetic lineages of these elements (Piégu et al. 2015).

As our ability to detect and characterize TEs across species improves, so will our evolutionary models. A striking feature of TE biology is that TEs are very common in the genomes of some species, but virtually absent in the genomes of others. For example, TEs represent more than $80 \%$ of the maize genome, but less than $1 \%$ of that of the bdelloid rotifer (Schnable et al. 2009; Flot et al. 2013). As a consequence, population genetic models of TE evolution have usually considered how transposition and excision rate, selection, and drift may interact to determine whether the stable copy number of TEs in a population will be relatively high or low (Ågren and Wright 2015). Several recent reviews discuss the success and refinements of these models in light of the rapid influx of whole genome data from model and non-model organisms alike (Lee and Langley 2010; González and Petrov 2012; Barrón et al. 2014). However, an almost equally striking observation, but one that has received less attention, is that the type of TEs that has become most abundant also differ dramatically between species. For example, in many plants long terminal retrotransposons such as Copia make up the bulk of the TE load, whereas in mammals like humans they are very rare and Alu elements are dominant (Cordaux and Batzer 2009; El Baidouri and Panaud 2013). To what extent this difference is due to historical contingency, and how much reflects selection at the TE level that allows them to spread successfully in some species but not others, remains unclear. This is an area where the Mobile DNA III offers plenty of molecular mechanisms to be incorporated into evolutionary models.

Finally, another aspect of TE biology that emerges throughout the book is the number of ways in which TEs may affect the organisms in which they reside. Biologists have had a rather ambivalent attitude to this point, and there has been much debate over the potential for TE induced phenotypic evolution. On the one hand, the idea of a key role for TEs in adaptive evolution goes back to the earliest days of TE biology. In fact, the discoverer of TEs, Barbara McClintock, never liked the term transposable element. Instead, she preferred 'controlling elements', a name obviously linked to her hypothesis, now discredited, that the main role of TEs was to regulate gene expression in an adaptive way. On the other hand, many genome biologists have often assumed that TEs are selectively irrelevant, which has lead to a bias against TEs in functional genome studies. As Lisch (2013) pointed out, this unfortunate attitude is well illustrated by the name of the most widely used tool for TE identification, RepeatMasker (Smit et al. 2015), reveals an attitude that such elements can be removed with little consequence.

In sum, as an overview to current state of our understanding of the molecular biology of TEs, Mobile DNA III is second to none. While the book largely lacks an evolutionary focus, it is a treasure trove for TE natural history. Overall, the book demonstrates how rich and dynamic the current study of TEs is: transposon biology will be an exciting field for many years to come.

\section{Abbreviation \\ TE: transposable element.}

\section{Authors' contributions}

$J A \AA$ conceived of the review, and both authors wrote it. Both authors read and approved the final manuscript.

\section{Author details \\ ${ }^{1}$ Department of Integrative Biology, University of Guelph, Guelph, ON N1G 2W1, Canada. ${ }^{2}$ Department of Molecular Biology and Genetics, Cornell Uni- versity, Ithaca, NY 14853, USA.}

\section{Competing interests}

The authors declare that they have no competing interests.

Received: 14 May 2016 Accepted: 19 May 2016

Published online: 27 May 2016

\footnotetext{
References

Ågren JA, Wright SI. Selfish genetic elements and plant genome size evolution. Trends Plant Sci. 2015;20(4):195-6.

Aziz RK, Breitbart M, Edwards RA. Transposases are the most abundant, most ubiquitous genes in nature. Nucleic Acids Res. 2010;38(13):4207-17. Barrón MG, Fiston-Lavier AS, Petrov DA, González-Perez J. Population genomics of transposable elements in Drosophila. Ann Rev Genet. 2014;48:561-81.

Cordaux R, Batzer MA. The impact of retrotransposons on human genome evolution. Nat Rev Genet. 2009;10(10):691-703.

El Baidouri M, Panaud O. Comparative genomic paleontology across plant kingdom reveals the dynamics of TE-driven genome evolution. Genome Biol Evol. 2013;5(5):954-65.

Elliott TA, Gregory TR. Do larger genomes contain more diverse transposable elements? BMC Evol Biol. 2015;15:69.

Finnegan DJ. Eukaryotic transposable elements and genome evolution. Trends Genet. 1989;5(4):103-7.

Flot JF, Hespeels B, Li X, Noel B, Arkhipova I, Danchin EGJ, et al. Genomic evidence for ameiotic evolution in the bdelloid rotifer Adineta vaga. Nature. 2013;500:453-7.

González J, Petrov DA. Evolution of genome content: population dynamics of transposable elements in flies and humans. In: Anisimova M, editor. Evolutionary genomics: statistical and computational methods. New York: Springer; 2012. p. 361-83.
} 
Hoen DR, Hickey G, Bourque G, Casacuberta J, Cordaux R, Feschotte C, FistonLavier AS, Hua-Van A, Hubley R, Kapusta A, Lerat E, Maumus F, Pollock DD, Quesneville H, Smit A, Wheeler TJ, Bureau TE, Blanchette M. A call for benchmarking transposable element annotation methods. Mobile DNA. 2015;6:13.

Janicki M, Rooke R, Yang G. Bioinformatic and genomic analysis of transposable elements in eukaryotic genomes. Chromosome Res. 2011;19:787.

Lee YC, Langley CH. Transposable elements in natural populations of Drosophila melanogaster. Philos Trans R Soc B Biol Sci. 2010;365(1544):1219-28.

Lisch D. How important are transposons for plant evolution?. Nat Rev Genet. 2013;14(1):49-61.

Piégu B, Bire S, Arensburger P, Bigot Y. A survey of transposable element classification systems-a call for a fundamental update to meet the challenge of their diversity and complexity. Mol Phylogenet Evol. 2015;86:90-109.
Platt RN, Blanco-Berdugo L, Ray DA. Accurate transposable element annotation is vital when analyzing new genome assemblies. Genome Biol Evol. 2016;8(2):403-10.

Schnable PS, Ware D, Fulton RS, Stein JC, Wei F, Pasternak SC, et al. The B73 maize genome: complexity, diversity, and dynamics. Science. 2009;326:1112-5.

Smit AFA, Hubley R, Green P. Repeat Masker Open-4.0. (2013-2015) <http:// www.repeatmasker.org>.

Wicker T, Sabot F, Hua-Van A, Bennetzen JL, Capy P, Chalhoub B, Flavell A, Leroy P, Morgante M, Panaud O, Paux E, SanMiguel P, Schulman AH. A unified classification system for eukaryotic transposable elements. Nat Rev Genet. 2007;8(12):973-82.

\section{Submit your manuscript to a SpringerOpen ${ }^{\circ}$ journal and benefit from:}

- Convenient online submission

- Rigorous peer review

- Immediate publication on acceptance

- Open access: articles freely available online

- High visibility within the field

- Retaining the copyright to your article 